\title{
DARIÉN, EL OTRO RETO DEL PANAMÁ DEL SIGLO XXI
}

\section{DARIÉN, ANOTHER CHALLENGE FOR PANAMA IN XXI CENTURY}

\section{AUTORA}

\section{Silvia Balanza}

Licenciada en Periodismo por la Universidad de Navarra (España). Profesora en la Universidad de Panamá. (Panamá). Periodista en El Universa/de Panamá.

silviabalanza@hotmail.com

\section{RESUMEN}

Gracias al Canal de Panamá, esta ciudad podrá demostrar que puede manejarlo y unirse al desarrollo. Este canal es una gran vía de comercio que ha dado peso internacional y estabilidad política a panameños, nicaragüenses, salvadoreños o colombianos. Este apogeo sufre peligro debido a la Guerra de Colombia, la cual perjudica, sobre todo a una pequeña región llamada Damién, que, en contraste con Panamá, centro financiero y lugar de comercio, es sumamente pobre, subdesarrollada y está totalmente incomunicada. Para evitar que uno de los pulmones del mundo, el desarrollo que genera el canal y la región de Damién sufran graves daños que se expandirían por el resto de los países, los medios de comunicación deben jugar un papel importante y noticiar lo que está pasando y las injusticias que se están cometiendo.

\section{PALABRAS CLAVE}

Canal de Panamá - Siglo XXI - Darién - Guerra 


\section{ABSTRACT}

Thanks to the Panama Canal, the city can prove he can handle it and join the development. This channel is a great way trade that has given international clout and political stability to Panamanians, Nicaraguans, Salvadorans and Colombians. This peak wals the tightrope because of the war in Colombia, which hurts, especially to a small region called Damian, who, in contrast with Panama, the financial and trading place, is extremely poor, underdeveloped and is completely isolated. To prevent one of the world's lungs, the development generated by the channel and the region suffer severe damage from Damien that would expand for the rest of the countries, the media should play an important role and Spreads what news is happening and the injustices being committed.

\section{KEY WORDS}

Panama Canal - XXI Century - Darién - War

\section{INDICE}

1. Introducción: El auge de Panamá

2. Desarrollo: Darién, la ciudad olvidada

3. Conclusiones: El reto panameño 


\section{Introducción: El auge de Panamá}

Todos sabemos que el gran reto de Panamá en el siglo XXI va a ser demostrar que puede manejar el Canal y además subirse al carro del desarrollo. El país se encuentra en la vanguardia de las economías de Centroamérica. Es el centro financiero y lugar de comercio por antonomasia. No cabe duda de que la situación de los panameños es mucho mejor que la de los nicaragüenses, salvadoreños o colombianos. El Canal le ha dado peso internacional y goza de estabilidad política en una democracia que apenas alcanza los 10 años. En esta década, el desarrollo ha sido imparable y la ciudad ha visto como poco a poco, los rascacielos han pasado a formar parte del paisaje diario, mientras las inversiones crecían. Ahora, hay que mantener estas magníficas perspectivas, pero existe un punto débil. La olvidada región del Darién que, dada su posición geográfica, debe protegerse, porque la seguridad del país está en juego y además el desarrollo debe ser uniforme en la medida de lo posible. Por eso, la discriminación que sufre la zona puede traer problemas a largo plazo. Representa el "otro reto del Panamá del siglo que viene".

\section{Desarrollo: Darién, la ciudad olvidada}

Darién es la provincia más extensa de Panamá, la más olvidada, bella, desconocida y temida. Tiene $16.803 \mathrm{~km} 2$ de selva, y se encuentra en la frontera con Colombia. Es uno de los pulmones del mundo que acoge a cientos de especies animales y vegetales y sus múltiples zonas pantanosas la convierten en una de las selvas más peligrosas de Iberoamérica. El Darién se divide en 2 distritos: Chepigana y Pinogana. Además, el Darién está conformado por 18 corregimientos y la capital es La Palma. Limita al Norte con la provincia de Colón, al NO. con la de Panamá, al Sur con Colombia y al Oeste con el Golfo de Panamá. En ella el conflicto con el país vecino está presente. Sus habitantes sólo quieren vivir en paz, aunque no siempre sea 
(8)

ISSN: 1576-3420 DOI: http://dx.doi.org/10.15198/seeci.2001.7.12-20

posible. Desde 1964, año de la fundación de las FARC, Darién ha sido asediada por grupos guerrilleros, paramilitares, unidades del ejército colombiano, traficantes de drogas e inmigrantes que se ocultan en la espesa selva conocida como "El Tapón del Darién".

Muchos colombianos se han refugiado en ella huyendo de la guerra, otros han decidido hacer negocio del conflicto y comerciar con darienitas y colombianos de uno y otro lado. El Darién se ha convertido en un tema de seguridad nacional, así lo declaró la exministra de Justicia, Mariela Sagel y el nuevo gabinete de Moscoso continúa en esa línea.

El comercio se basa en el tráfico de armas, drogas, comida, y actividades de intercambio de información con los grupos armados. De hecho, recientemente se ha creado una oficina para que los colombianos que ingresen en Panamá lo hagan de forma legal. Pero no son sólo los colombianos los que huyen de sus casas. El miedo ha conducido a que comunidades indígenas abandonen sus hogares y emigren en busca de paz. Como caso más reciente, a comienzos de junio la localidad de La Miel fue saqueada por supuestos guerrilleros. Huyeron del área 163 personas. Otro incidente destacable fue el que se produjo en Boca de Cupe en noviembre de 1997 cuando unos 60 hombres armados tomaron durante 3 horas la localidad. También en 1997 se decretó el toque de queda en el distrito de Pinogana. El 18 de febrero de 1998 un grupo de bandoleros atacó el poblado de Capetí, cercano a la frontera y en la reyerta murió un colombiano y otros 2 fueron detenidos. Ya el 20 de abril de este año, el poblado colombiano fronterizo de Sapzurro fue convertido en base de las FARC. La situación no es de guerra, pero los indígenas sienten temor porque se encuentran incomunicados, y abandonados por el resto de país ante un conflicto ajeno. Son tribus emberá, waunaan y kuna las que habitan un medio tan bello como hostil. Un lugar rico en fauna y flora, considerado uno de los pulmones del mundo, pero precisamente por ese olor salvaje, olvidado. 


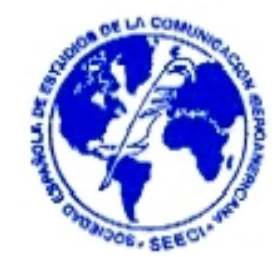

Para los medios de comunicación españoles es un tema de interés por varias razones; primera porque en nuestro país hay un gran seguimiento del conflicto colombiano y esta región panameña sufre en sus propias carnes esta guerra, ya que en la selva no hay frontera, ni puestos de control de tal forma que uno no sabe cuándo está en Panamá y cuando en la problemática región de Urabá, en la que las guerrillas tienen mucha fuerza. Por otra parte, la cooperación de las ONG con Colombia es muy fuerte y a tan sólo unos kilómetros los indígenas darienitas viven peor y nadie se acuerda de ellos. Después de la fiebre despertada por el Huracán Mitch empezó la preocupación por Nicaragua, Guatemala y El Salvador, y sin embargo esa solidaridad se limita a los lugares señalados por el poderoso dedo de los medios de comunicación. Panamá necesita apoyo internacional para proteger su frontera y a sus habitantes. No se puede olvidar que la seguridad del país es fundamental para el resto del mundo porque en caso de que le ocurriera algo al Canal, miles de empresas sufrirían pérdidas astronómicas.

Pero para Panamá es un tema crucial. Primero porque la provincia de Panamá limita con El Darién. Si a los guerrilleros colombianos o a los paramilitares se les ocurriera llegar a las puertas de la capital atravesando la selva se produciría un grave conflicto internacional. Además, no podemos olvidar la presencia de EE.UU. En los Tratados Torrijos-Carter, por los cuales se negoció la reversión del Canal a Panamá, existe una cláusula que indica que en el supuesto de que la seguridad del Canal se viera alterada, los norteamericanos podrían regresar a sus bases y defenderlo. Lo mejor es que no indican cuales son los supuestos de peligrosidad del Canal.

El 22 de junio de 1.999 el General Charles Wilhein, ante la comisión de relaciones exteriores del Senado de los EE.UU, declaró que "la fuerza publica de Panamá no esta organizada, ni equipada para enfrentar incursiones de los insurgentes colombianos en las provincias del Darién y San Blas". Según este General el problema de la frontera entre Panamá y Colombia pone en peligro la seguridad del Canal Marítimo. De hecho el Gobierno estadounidense ha hecho público su interés 
por construir una base militar en el Darién "para proteger la frontera y luchar contra el narcotráfico". En definitiva, el Darién es una bomba de relojería a la que nadie hace caso.

También debemos tener en cuenta que los recursos de Panamá son limitados y la zona necesita un sofisticado sistema de seguridad, que, hoy por hoy, no se puede permitir el Estado Panameño. Hace tres años, José Luis Sosa, el que hasta hace unos meses era Director de la Policía Panameña, junto con el Obispo del Darién, Monseñor Rómulo Emiliani, inició un plan que incluía el aumento de unidades fronterizas, así como la construcción de cuarteles en las zonas de riesgo. En el mes de agosto se inauguraron dos cuarteles, uno en Metetí, localidad en la que reside Emiliani, y otra en Boca de Cupe, un punto negro en la geografía del Darién. El pasado 26 de agosto cuando Sosa realizó su último viaje al Darién recordaba que, al llegar al cargo, la policía que iba de caserío en caserío no estaba bien vista porque la gente de ese caserío comerciaba con los de uno y otro lado y la presencia policial terminaba con el negocio. Una de las localidades que visitó en esa última travesía fue Paya. Este poblado se encuentra a tan sólo tres kilómetros de la frontera con Colombia. Entonces, el Cacique Mayor, Enrique Martínez ofreció la colaboración de su pueblo por primera vez a la policía. Algunos campesinos nos comentaron en aquel viaje que se sentían desprotegidos y olvidados, y que necesitaban a alguien que los defienda. Y es que la situación de esta pobre gente es muy complicada.

Se puede viajar por el Darién de tres maneras. La primera es en canoa por el Tuira y el Chucunagre, que son los ríos más caudalosos. Aunque es un medio lento e inseguro por los caimanes que habitan en sus aguas. La segunda opción es por carretera. Los caminos escasean y se encuentran en unas pésimas condiciones de tal manera que ir de Panamá City a Darién puede costar dos o tres días, dependiendo de la zona del Darién a la que nos dirijamos. Así que el medio de transporte idóneo es el helicóptero porque permite aterrizar en lugares difíciles y es rápido y seguro. Pero no está al alcance de los darienitas viajar en helicóptero, por lo que el comercio 
de la región es realmente complicado. Un ejemplo. Una pieza de ropa interior en el Darién cuesta 5 dólares. Es un precio desorbitado si tenemos en cuenta que en la capital con ese dinero uno se puede comparar una camisa 0 ir a comer a un restaurante medio. Llegan pocos productos, viven con luz de paneles solares, no tienen agua, y muchos niños no han visto nunca una cámara de fotos. Sus condiciones de vida son primitivas a las puertas del siglo XXI. ¿Cómo puede esta gente subsistir en condiciones dignas sin una ayuda? y ¿cómo pueden defenderse del peligro que representa la guerra colombiana?

Lo cierto es que según un comunicado emitido por las Farc "de acuerdo a la Octava Conferencia Nacional de Guerrilleros celebrada en el año 1993, las Farc determinó la no intervención fuera de las fronteras de Colombia, esperando reciprocidad en el trato". Por tanto niegan su entrada en el Darién.

\section{Conclusiones: El reto panameño}

No cabe duda de que Panamá se enfrenta a un enorme reto a partir del 31 de octubre con la Reversión del Canal. Debe mostrarse como un país preparado para administrar la "puerta del mundo" ya que el comercio marítimo mundial depende en gran parte de ello. Pero sin una seguridad en la zona la imagen del país puede verse deteriorada. Panamá está en auge, tiene una de las economías más prósperas de América Latina con apenas un $1 \%$ de inflación. Las inversiones son muy buenas y cuenta con llaves como el Canal y Zona Libre de Colón que son rentables. Hoy pocos dudan de la capacidad de los panameños para administrar al Canal ya que el $97 \%$ de los trabajadores lo son y llevan años manejando el funcionamiento canalero. Sin embargo no se puede olvidar el Darién, primero porque es una fuente de recursos naturales muy importante, segundo porque si no se cuida como es debido, la guerra colombiana puede afectar directamente a Panamá y tercero porque allí vive gente. 
Me ha impresionado ver como en Panamá se ve a Darién como la provincia fantasma. Allí habitan indígenas, pobres a los que nadie hace caso, excepto cuando ocurre algo y todo el mundo se apiada de ellos. Viven incomunicados, en unas condiciones de vida primitivas. Practican una ganadería y agricultura de subsistencia en un medio tan hostil como es la selva. Panamá es sin duda un lugar de contrastes. Parece inconcebible que a tan sólo 60 kilómetros de distancia, (media hora en avión) puedan existir sitios tan distintos como Paitilla, con sus rascacielos de los grandes bancos del mundo y unos poblados en los que los indígenas sobreviven a duras penas conviviendo con una guerra que dura ya 35 años y que está desangrando Colombia. El Panamá del siglo XXI debe empezar a limar las grandes diferencias que acoge. Un país pequeño y próspero como es, no puede permitirse el lujo de abandonar a su suerte su provincia más grande y mucho menos si es, en opinión de Emiliani, "la frontera más peligrosa de América Latina". Es el otro reto de Panamá, un reto callado, difícil, pero indispensable para que el siglo que viene el país se suba al carro del desarrollo. Sin duda Panamá tiene muchas posibilidades de desarrollo si aprovecha la herencia dejada por los norteamericanos tras 85 años de ocupación. Apenas hace 10 años que se apartó a Noriega del poder. Es por tanto una democracia joven, pero con grandes cualidades a la que hay que ayudar y proteger. Ahora, lo complicado es saber qué hacer con esas cualidades y tratar de conseguir un desarrollo uniforme por lo que el Darién debe ser un reto fundamental no sólo porque allí viven los panameños más pobres y necesitados sino por la propia seguridad del país y del Canal.

Por todo esto, los medios de comunicación son indispensables para mejorar las condiciones de vida en el Darién. Para la mayoría de la gente, sólo existe lo que sale en los medios de comunicación, y así se ha demostrado en muchas ocasiones. Por eso ya que tanto interesa la guerra de Colombia y todo lo relacionado con ella, sería interesante que se conociera el tema no sólo en España sino en el resto del mundo porque es la única manera de que se ofrezca una ayuda abierta al Darién. En esta aldea global en la que vivimos, los medios obran el milagro de que lo que ocurre en 
un rincón perdido, se conozca en el resto el mundo. De todas formas, es triste el hecho de que siempre que se hable de Latinoamérica en los medios de comunicación occidentales sea por causa de una guerra o de una desgracia. De hecho, Panamá desde la caída de Noriega apenas sale en los medios españoles. Por eso un flujo de información mayor en el que las noticias sean regulares y el conocimiento de estos países crezca, afianzará los lazos de unión entre los pueblos.

Muchas gracias. 